\title{
A LINGÜÍSTICA APLICADA EM CONTEXTO DIGITAL E O ENSINO DE GREGO NA WEB: PRIMEIRAS CONSIDERAÇÕES
}

Anise A. G. D’O. Ferreira*

\begin{abstract}
RESÜMO: Este artigo defende a posição de que a Lingüistica Aplicada pode contribuir para o desenvolvimento e implementação de ensino da Lingua Grega antiga no contexto da Web, apesar de tradicionalmente não estar associada às Letras Clássicas. São apontadas algumas possiveis contribuiçōes para o ensino aprendizagem de grego com relaçāo à abordagem instrumental, à visão social de lingua e aprendizagem, aos processos de compreensão de leitura, à Lingüística de Corpus e aos estudos de interação. Algumas consideraçōes preliminares para o desenho de curso de Grego on-line são propostas, baseadas nas pesquisas multifacetadas da Lingüistica Aplicada ao ensino/aprendizagem em contexto digital.
\end{abstract}

PALAVRAS-CHAVE: Lingüistica Aplicada e Letras Clássicas; curso de Grego on-line; Lingüistica Aplicada no ensino de grego; ensino/aprendizagem de grego na Web, linguagem; ensino de grego na Internet.

\section{Introdução}

1 ste artigo tem por objetivo iniciar uma reflexão sobre a tica Aplicada (LA) ao ensino-aprendizagem de grego antigo para adultos no âmbito do contexto digital da Web e da Internet e, a partir

Pontificia Universidade Católica de são Paulo - PUC-SP. 
FeRreira, Anise A. G. D’O. A Lingüistica Aplicada em contexto digital e o ensino de gregon

dela, chegar a considerações preliminares para uma proposta de desenvolvimento e pesquisa ae ensino/aprendizagem de grego nesse contexto.

Antes de abordar a LA emi contexto digital propriamente dito e sua relação com o ensino e a aprendizagem de grego antigo, è preciso ressaltar a abrangência de foco da pesquisa em LA. A LA aborda a língua associada a contextos de uso e às práticas sociais que envolvem o entendimento da lingua, tentando não separar a teoria da prática; na esfera educacional, a LA investiga procedimentos relevantes para a formulação de princípios pedagógicos relativos à linguagem (Cook e Seidlhofer, 1995). Não se pretende discutir aqui o status da LA como disciplina. Tal debate, embora ainda possa fomentar posições interessantes de ordem política e teórica, tem o seu lugar nas vozes de outros pesquisadores (Celani, 1992; Signorini; Cavalcanti, 1998; Cook e Seidlhofer, 1995: Rajagopalan, 1999). Vale destacar, contudo, a vocação transdisoiplinar da LA e os tópicos preferenciais a que se dedicam os lingüistas que atuam no âmbito da LA. Paschoal e Celani (1992) apresentam cinco focos da LA: a pesquisa em sala de aula, a aquisição de linguagem, as metodologias de ensino de linguas para fins especificos, os processos de leitura e compreensão, as descrições de uso da lingua em diferentes contextos e as implicações culturais do ensino-aprendizagem de língua. No ãmbito da língua estrangeira (LE). Lopes (1999: s.p. $)^{1}$ aponta as tendências predominantes dos últimos 30 anos:

Nota-se uma preponderãncia da análise de questões de ensino/aprendizagem de LEs, inicialmente, de uma perspectiva de aplicação de princípios da Lingüística ao ensino, em que o que ocorre em sala de aula não é considerado e, posteriormente, dentro da tradição de pesquisa de diagnóstico e de intervenção em sala de aula, em que o processo de enșino/

Ass citações de Lopes, 1999, foram extraídas de documento digital nắo paginado. 
Rev. ANPOLL, n. 15, p, 11-41, jul./dez. 2003.

aprendizagem em sala de aula é levado diretámentè em consideração. Esta segunda tradição já se encontra dentro da concepção contemporânea de Lingüistica Aplicada. O segundo tópico prestigiado é leitura, o que parece ser revelador da importância que o campo da leitura em LE alcançou no Brasil, tendo em vista o fato de os pesquisadores terem, em seus projetos, passado a considerar a relevância social da apren dizagem de uma LE.

A pesquisa em LA vem contribuindo, assim, para o entendimento dos processos de ensino-aprendizagem de língua estrangeira e de leitura principalmente. Em seu levantamento, Lopes assinala, entre os tópicos de interesse da LA, a elaboração e avaliaçāo de material didático, formaçāo do professor, planejamento de cursos, análise do discurso/pragmática em LE, produção escrita, análise de erros, ensino de LE por computador, anâlise da interação oral em sala de aula, produção escrita, descrição de aspecto sistêmico da LE etc. Menciona, entre as áreas a serem desenvolvidas, as novas tecnologias e o processo de ensino/aprendizagem de LEs presencial e à distāncia. Além do estudo de Lopes, o relatório das atividades do GT de LA divulgado pela ANPOLL (Meurer e Gimenez, 1998-2000) destaca cinco focos de pesquisa: transculturalidade, linguagem e educação; português como L2/LE; formação de professores de língua; teorias do gênero em práticas sociais; e ensino e aprendizagem de linguas.

Como era de se esperar, as linguas clássicas não são uma preocupação usual entre os lingüistas que atuam em LA. São as línguas modernas as linguas estrangeiras encontradas preferencialmente nas pesquisas da LA, com predomínio da língua inglesa, a qual Lopes, mesmo defendendo uma política de educação multilíngüe, julga ser um alvo importante da educação para se viver um mundo globalizado. O grego antigo, em tese, nāo entra na categoria de LE, nomenclatura dada a uma língua moderna, sendo tratada como uma língua clássica, ancestral da lingua materna. Todavia, o grego poderia ser considerado uma lingua estrangeira, tendo em vista os 
FErreira, Anise A. G. D'O. A Lingüística Aplicada em contexto digital e o ensino de grego.

processos envolvidos na aprendizagem de um sistema lingüístico que é estranho ao português; alēm disso, pressupõe o desenvolvimento da leitura, que depende de um contexto de ensino/aprendizagem de língua apropriado, o que costuma ser objeto de preocupação dos que trabalham com LA. O fato de não ser uma lingua falada hoje, não significa que não tenha uso; como texto lido, desempenha papel importante na comunicação textual, em língua materna ou estrangeira, e na compreensão de outros textos. A reflexão proposta neste artigo visa a defender a postura de que as contribuiçōes da LA não só são pertinentes para as línguas modernas, mas também para o ensino de Letras Clássicas, especialmente para o ensino e a aprendizagem do grego antigo que é a língua de interesse da autora. E como a LA atualmente estende-se também aos dominios da compreensão da linguagem no universo digital (Chanier, 1998; Chanier e Pothier, 1998; Barbot, 1998), haja vista a própria inclusão de um número desta revista dedicado à linguagem e Web, lingüistas e classicistas poderiam trabalhar juntos na esfera do ensino e da aprendizagem de grego em contexto digital.

\section{Algumas contribuições da LA}

Dentre as contribuições da LA no paî́s, Lopes (1999) destaca o Projeto Nacional de Ensino de Inglês Instrumental (PEII), cuja criação "acompanha desenvolvimentos teóricos e metodológicos, na área de ensino das línguas em geral (não só em LEs), que apontam que as pessoas aprendem linguas com propósitos variados e que, portanto, a eficiência de um programa de eńsino pode ser aumentada se focalizar, diretamente, os objetivos específicos dos aprendizes". Afirma que a critica ao ensino de inglês acabou afetando professores que não estavam envolvidos no projeto, como professores de outras LEs e de lingua materna. A abordagem instrumental continua atraindo pesquisadores que trabalham com diferentes linguas (Ramos e Freire, 2002). Uma das marcas do en- 
Rev. ANPOLL, n. 15, p. $11-41$, jul./dez. 2003.

sino instrumental é o levantamento e análise de necessidades (Hutchinson; Waters, 1987), cujas possibilidades foram estudadas por Collins (1992), entre outros. Uma análise de necessidades costuma possuir um escopo abrangente envolvendo tanto as necessidades e desejos lingüisticos, quanto as estratégias cognitivas, sociais e comunicativas requeridas pelo contexto ou situação de uso.

O que se pode dizer do impacto que tal abordagem teria no ensino de grego é que há diferentes propósitos também para o estudo da língua grega, e uma parcela muito reduzida dos estudantes de Letras se torna professor de lingua ou de literatura grega, ou mesmo tradutor para um mercado editorial. Há de se considerar um possivel universo de profissionais dentro da área de humanas que podem nắ ser só fascinados pela cultura grega, mas também podem precisar conhecê-la para aperfeiçoarem sua atividade profissional; sem contar os profissionais de Letras que podem ter tido algumas aulas de grego na graduação, existem os psicólogos, psicanalistas, filósofos, historiadores, jornalistas, entre outros, que já fazem, gostariam de fazer ou precisariam fazer usos especificos da lingua grega. A ausência do estudo de lingua e literatura grega no curriculum do ensino médio e a reduzida oferta de cursos em nivel de extensão ou nivel superior voltados para diferentes públicos pode: justificar essa demanda. Um estudo de populações-alvo almejando fins especificos de uso da língua grega poderia ser uma estratégia relevante na proposição de cursos também específicos.

A adoção de uma perspectiva instrumental e centrada no aluno se faz notar no ensino de grego moderno, como por exemplo, no Athina Project, ${ }^{2}$ que apresenta os resultados de sua análise de necessidades, seguindo a tendência de abordagens de outras linguas modernas. Por meio dela, verificou-se que os interesses dos alunos

2 Projeto iniciado em 1996, pela iniciativa de Ellinogermaniki Agogi e das Universidades Erlangen e:Complutense-Madrid (cf. http://www2.ellinogermaniki.gr/ep/athina/ AthCon.htm). 


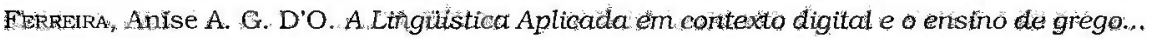

variavam bastante; entre esses interesses incliti-se a curiosidade acadêmica de conhecer as diferenças entre grego moderno e antigo. Ter uma preocupação com os diferentes propósitos do estudo da lingua grega é também assumir uma postura em sintonia com a questão tratada a seguir.

Do ponto de vista teórico, Lopes refere-se à adoção de abordagens que se centram em visões socioculturais da cognição e da linguagem:

A área parece que será cada vez mais informada por teorias que vêem o discurso e a aprendizagem como situados na e constitutivos da vida social, levando à compreensão de que o aprendiz tem uma sócio-história do qual é participante com suas marcas sociais. A vinculação do aprendiz a sua socio-histórica parece ser essencial para a compreensão dos processos de ensinar/aprender LEs. Isso quer dizer que antevejo o uso de teorias sobre o discurso e aprendizagem que, claramente, reconhecem que o aprendiz/participante do discurso tem corpo (classe social, gênero, sexualidade, raça etc.) e não somente estrutura cognitiva.

Uma visão social da linguagem pode ser notada, tanto no nível do aprendiz (professor ou aluno), considerando-se as contingências sociais da aprendizagem da lingua, quanto no nivel da lingua propriamente dita, considerando as contingências e funções sociais para a produção de sentidos, i.e., para o entendimento e produção de linguagem. Assim, vêem-se trabalhos dentro da LA que refletem essas contingências sociais, por exemplo, em estudos que mostram as diferenças, entre teoria e prática no discurso em sala de aula e a conscientização do professor (Liberali, 1996; Magalhães, 1996); ou, ainda, nos estudos que ressaltam as questões de gênero, seja com foco na descrição, seja com foco no universo do ensino/aprendizagem (Machado, 1996; Dionisio, Machado e Bezerra, 2002). Levantamentos dos estudos na área da Lingüística Textual, de textos e discursos confirmam a tendência de adoção de uma perspectiva sociointeracional no tratamento da linguagem (Koch, 
Revi ANPOLL, n. 15, p. 1 1-41, jul./dez, 2003.

1999; Barros, 1999). Essa visão permeia também as abordagens gramaticais de linha funcionalista, em que o sistema é visto como um quadro de referência de uso e toma a semântica como base (Neves, 2001; Eggins, 1994; Halliday, 1994).

Mas o que acontece com o ensino e a aprendizagem do grego antigo, que não é uma língua empregada ativamente nos atos de comunicação social do mesmo modo que uma língua moderna? A literatura científica não tem sido muito pródiga nesse sentido. Há algumas publicações estrangeiras que tratam do ensino até os anos sessenta (Moreland, 1981), ou de um método inovador dos anos setenta (Casler, 1980) ou do levantamento estatístico do ensino de grego na Inglaterra (CUCD, 1995-1998) ou, ainda, da história do ensino de grego na Espanha (Orcera, 2002); nacionalmente, as publicações divulgadas são escassas, tratando de aspectos históricoInstitucionais e linhas acadêmicas (Cardoso, 1994; Starzynsli, 1994; Hirata, 1994; Correa, 2001). Um só grupo de pesquisa foi encontrado na base de dados do $\mathrm{CNPq}^{3}$ atuando na linha de produção de material didático, portanto, voltado a questões de ensino e aprendizagem, com publicação referente à língua latina. $\mathrm{E}$ apenas uma tese que oferece uma descrição da língua visando ao ensino (Murachco, 1998) aparece na base de teses do IBICT. De qualquer modo, ninguém espera aprender grego antigo em escolas de idiomas; raramente no segundo grau, uma vez que não é matéria obrigatória do curriculum escolar, apesar de alguns esforços para fundamentar a importância dos estudos clássicos no ensino médio (Fiorin, 1991). Vez ou outra ouvimos falar de algumás exceções, instituições privadas ou religiosas, díspostas a arcar, voluntariamente, com o õnus de tal adoção (tempo, professor, sala etc). O foco principal

3. Linha: Produção de material didătico em línguas e literaturas clássicas, do grupo Cultura e Sociedade na Antigüidade Clássica, liderado por Jacyntho Brandāo, UFMG. A produçāo divulgada refere-se ao ensino do latim por Antonio Martinez de Rezende (1999): A Forma e o Sentido da Gramática, comunicação apresentada na XI Reuniāo Nacional de Estudos Clâssicos (Araraquara), na sessão "Questōes de expressividade em língua latina". 
FERrerra, Anise A. G. D'O. A Lingüistica Aplicada em contexto digital e o ensino de grego...

đe aprendizagem lingüistica é a habilidade de leitura. A escrita, a comunicação oral e até mesmo a compreensão de grego antigo falado (de textos $)^{4}$ não são habilidades previstas no ensino dessa língua. Não há evidências suficientes de uso da lingua como fala espontânea da comunicação natural, nas diferentes épocas e contextos em que foi empregada. A oralidade presente nas obras é resultado de uma composição escrita elaborada. Sendo assim, o grego antigo não é utilizado hoje para se comunicar com alguém, seja por escrito, seja oralmente. Quem está interessado na língua, então, pode matricular-se em disciplinas de graduação ou em um curso de extensão oferecido por instituições de ensino superior no país, ou por centros isolados de estudos. Pode, ainda, procurar algum professor particular e compor um grupo de estudos.

Á língua grega é descrita por meio de uma gramática complexa e os livros de gramática e sintaxe (Smyth, 1920-1984; Ragon, 1979; Humbert, 1960-1986; Perfeito, 1988; Freire, 1997) não dão conta de toda a variação de uso da língua, apesar de o universo da língua grega representar um corpus textual delimitado historicamente. O corpus das obras de literatura grega abrange um período histórico bastante longo, apresentando variações de época, desde o século VIII-VII a. C., até o grego moderno: o homérico ou arcaico, ático ou clássico, helenístico, romano, koiné, bizantino e moderno (Horrocks, 1997), sem contar as variações de estilo e gênero. A diferença entre grego antigo e moderno do ponto de vista de quem aprende a lingua pode ser tão grande que quem estuda grego moderno não é necessariamente capaz de ler uma obra em grego antigo. De fato, na Grécia atual, há publicações bilingües de textos antigos: grego antigo em uma página e grego moderno em outra. ${ }^{5}$ Apesar

4 Eventualmente, o hábito de ouvir e ler frases em voz alta, com pronúncias consisstentes, possibilita o reconhecimento de palavras e sentenças por input auditivo. O processo é, portanto, diferente do que ocorre com o grego moderno em que a pronúncia è conhecida e a comunicação oral é corrente.

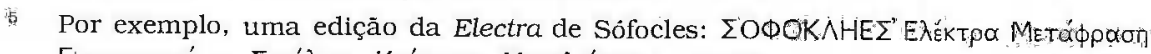

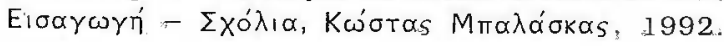


Rev. ANPOLL, n. 15, p. 11-41, jul./dez. 2003.

disśo, o alfabeto grego é o mésmo, com algumas inclusões fonéticas, uma diminuição dos casos e uma simplificação da sintaxe; também há muito em comum no vocabulário. (Horrocks, 1997; Pring, 1995):

Um ponto a levantar sobre o ensino e aprendizagem de grego é a visão de linguagem e de aprendizagem de lingua subjacentes a métodos ou materiais didáticos. Um dos indícios de uma visão social da lingua é a organização do método em torno de usos sociais padronizados da linguagem ou de funções comunicativas (Cunningsworth, 1984). Embora a análise de métodos seja um assunto bastante complexo e delicado na LA (Coracini, 1999a), convido o. leitor a lançar apenas um primeiro olhar sobre eles. Não tendo à disposição uma pesquisa que relate detalhadamente como os diferentes materiais didáticos para o ensino da lingua grega sãơ usados em sala de aula, podemos levantar algumas hipóteses sobre alguns métodos que estão disponiveis. Métodos contemporâneos de grego antigo conhecidos no meio escolar, tanto escritos em língua materna como estrangeira, tais como Mastronarde, (1993), Hansen e Guinn (1992), Ruck (1979), Debut (1987), Bar ros, (1962), Horta (1991) e Murachco (2001), apesar das diferenças de abrangência, quantidade e profundidade, apresentam suas lições organizadas em torno de tópicos gramaticais formais. Alguns podem ser confundidos com um livro de gramática acrescido de exercícios. Um deles, o método de grego clássico adotado nos cursos de extensão em Harvard, por exemplo, ê o Introduction to Attic Greek, (Mastronarde, 1993). O sumário do livro exibe a organização por tópicos gramaticais (figura 1"). O autor, um professor engajado na divulgação da lingua grega, é filiado à Universidade da California em Berkeley. Publica, sem restrições de acesso, em seu site pessoal, tutoriais e exercicios gramaticais, bem como ta-

As figuras estão disponiveis em http://lael.pucsp.br/ anise/artigo_anpoll.html

Cf. Mastronarde, Ancient Greek tutorials, http://socrates.berkeley.edu/ ancgreek/ 
FerreIra, Anise A. G. D'O. A Lingüistica Aplicada em contexto digital e o ensino de grego:

belas de paradigmas verbais e nominais. ${ }^{6}$ Apesar das boas recomendações de leitores e da crítica especializada (Halleran, 1993), uma opinião, em particular, sobre o método de Mastronarde chama a atenção para ilustrar a angústia do aluno em relação à aprendizagem da gramática:

I don't mean to be a spoílsport and detract from the glowing reviews, and I respect Mastronarde (having taken a class with him at UC Berkeley) but Ancient Greek is hard enough as it is without such a dry approach to learning it. The merits of this book are visible: it is Thorough in its explanation of grammar (but then so is Smyth - and one would hardly want to learn Greek from Smyth, would one?) and it never skimps on complex technical explanations of historical morphology: how certain words came to be spelled certain ways, and so on. But, although I despise language books that are Too. lackadaisically conversational ("Allons-y" being an example of this dreadful trend) a balance would have been appropriate and it has not been struck.

Yes, the aspiring linguist will be pleased with Mastronarde's explanation of linguistic changes over time resulting in quantitative metathesis. But there are no sentences until quite late in the book, which makes the experience of learning Greek a frustrating, algebraic exercise without payoff until much later - too late in fact. I am a highly motivated student and did extremely well in a class with an excellent teacher uising this book, but I would never use it in a million years in a class $I$ was teaching unless forced (which, I have heard, is the reason why it is used so widely in my school in the first place). I hated algebra, and I similarly hated memorizing Mastronarde's endless lists of noun declensions until I was blue in the face. Despite the occasionally interesting linguistic notes, I do not think that the earnest new student of Greek will find this book an enticing or very readable means of learning it. Hansen and Quinn was better, but paradoxically I found the "Teach Yourself" series" "Ancient Greek" to be much more enjoyable despite its brevity, and more colorful and fun. It had you do sentences immediately. There was life, action, and color in 
Rev̌. ANPOLL, n, 15, p. 11-41, jul./dez. 2003.

its presentation. Yes, noun declensions must be memorized, but there are easier ways than doing it all in the beginning as Mastronarde makes you do it. ${ }^{7}$ (Doran, 2002)

A julgar pela priorização de tópicos gramaticais formais na organização do conteúdo e tipos de exercícios existentes nos métodos, é possivel supor que a aprendizagem da leitura do grego é vista fundamentalmente como um processo de aplicação e de memorização de regras de gramàtica através de exercicios individuais de tradução e versão de frases ou trechos, autênticos ou não, que exigem diferentes niveis cognitivos, com pouca ou nenhuma contextualização. Em geral, não são sugeridas atividades colaborativas, pressupondo uma aprendizagem isolada com intervenção do professor. Também não parecem levar em conta necessidades especificas de alunos, supondo que todos vão aprender da mesma forma e os mesmos conteúdos, Qualquer visão diferente dessa precisaria ser observada na sala de aula e dependeria da abordagem e atitude do professor, em seu modo de trabalhar com o método e conduzir as tarefas.

Apessar de novidades em métodos poderem ser apenas superficiais e sua importância ser relativa no processo de aprendizagem (1999b) há, a meu ver, entre as publicações americanas, três tentativas um pouco diferenciadas dos métodos tradicionais em relação à visāo de lingua e sua aprendizagem, em virtude de um tratamento dos conteúdos. Uma delas, empregada na Universidade Brown, é o método Athenaze ${ }^{8}$ (Balme e Lawall, ${ }^{9}$ 1990), em dois volumes. As lições do primeiro livro estão organizadas em torno de textos curtos, narrativos, criados pelos autores, sobre a vida de um

7 Customer reviews, Amazon, http://www.amazon.com/exec/obidos/tg/stores/detail/. /books /0520201779/customer-reviews/ref=cm_rev_all_1/102-8310221-5220952

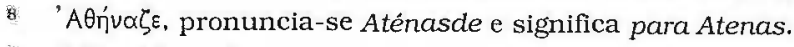

9 Gilbert Lawall é professor da Universidade de Massachusetts, engajado da divulga: ção do ensino da língua grega; possui um inventário sobre os cursos ministrados nọs EUA e distribui material para sala de aula em seu site pessoal: http://www-unix.oit. umass.edu/ glawall/ 
Ferreira, Anise A. G. D'O. A Lingüistica Aplicada em contexto digital e o ensino de grego....

camponềs chamado Diceôpolis, personagem homônima retratadạ pelo comediógrafo Aristófanes; um entre muitos camponeses que tiveram de ir para Atenas durante guerra do Peloponeso. Esses textos remetem a pontos gramaticais que se submetem à narrativa e aos diálogos de uma situação possivel, embora imaginária. O sumário apresenta o conteûdo das lições orgānizado pelos temas situacionais dos textos na coluna da esquerda, e pelos pontos gramaticais tratados em cada lição na coluna da direita (figura 2). Teoricamente, seria mais fácil memorizar o próprio código e os padrões de uso em virtude do significado gerado pela narrativa. Uma objeção corrente é que esse uso é uma ficção e não uma realidade do texto grego, ou seja, os textos não são autênticos, pelo menos, os das lições iniciais. Alguns leitores ${ }^{10}$ se queixam de que o livro é superficial nas explicações. para facilitar uma assimilação mais rápida, ou de não ser um livro apropriado para aqueles que desejam ser professores da lingua. De qualquer modo, o leitor é bastante provido de informações de contexto histörico e social da época clássica.

Um outro método de grego clássico que se destaca pela ênfase em estratégias cognitivas e uma visão mais moderna da língua é Greek for reading (Seligson; 1994). Recomendado pela critica (McMahon, 1994), o método se baseia em uma gramática funcional e o leitor é convidado a reconhecer speech acts e a desenvolver expectativas morfológicas, sintáticas, semãnticas \& pragmáticas, por meio de estudo de sentenças autênticas. No final do livro, a autora compila 124 sentenças básicas (períodos simples e compostos) que, teoricamente, sintetizam as diferentes estruturas morfológicas, sintáticas e funcionais da língua.

O terceiro método americano que tenta trazer alguma novidade é da Paula Saffire e Catherine Freis (1999), Ancient Greek Alive. Surpreendeu a crítica por sua inovação e abordagem (Torrance,

10 Cf. Customer reviews, Amazon, http:/ /www.amazon.com/exec/obidos/tg/detail/-/ $0195056213 /$ qid $=1034541161 / \mathrm{sr}=1-1 / \mathrm{ref}=\mathrm{sr}_{-} 1 \ldots 1 / 102-8310221-5220952 \mathrm{v}=$ glance 
Rev. ANPOLL, n. 15, p. 11-41, jul, /dez, 2003.

2000). Apesar de o livro estar organizado em torno de pontos gramaticais (figura 3; coluna esquerda) e de as leituras corresponderem (coluna da direita) a esses pontos, as autoras iniciam o método com scripts para serem praticados oralmente nas primeiras aulas, não só para facilitar a memorização, mas tambẻm para que o início da aprendizagem se estabeleça por meio de uma experiência mais ativa. Formada em Harvard, Paula Saffire conta que foi no oitavo mês da Pós-graduação que percebeu, pela primeira vez em sua vida, que a leitura/do grego lhe parecia natural. Para ela, esse fenômeno foi causado pelas oito horas diárias de leitura obrigatória impostas pela famosa "lista de leitura" exigida no programa. Tornou-se professora e, reavaliando sua própria experiência, intuiu que o modo de induzir seus alunos a um modo de leitura mais fácil e relaxada era proporcionar-lhes uma grande quantidade de "grego fácil".

É na Inglaterra que aparece, no final dos anos setenta, a preocupação com uma metodologia de ensino que questiona a eficiência dos métodos anteriores, o Reading Greek, editado pela Joint Association of Classical Teachers (JACT). Casler (1980) afirma que os métodos de ensino de lingua populares antes do Reading Greek haviam falhado no propósito de ensinar o grego. Os métodos eram a tradutção via gramática, abordagem indutiva, método audio-lingual e abordagem estrutural. Tais métodos, ao contrário do Reading Greek, não levavam em conta as caracteristicas do aprendiz adulto: necessidade de explicação detalhada do alfabeto, pouco tempo para estudar, além da questão da ausência de informantes vivos da lingua e da questão da relevância. A crítica especializada também foi favorảvel (Holoka, 1997). Possui semelhanças com o Athenaze por șer organizado por temas em textos narrativos e dialogados em torno da vida de um personagem, Diceópolis. Uma pesquisa executada pelo Conselho de Departamentos de Letras Clássicas das universidades britânicas (CUCD, 1995-1998) apontou que Reading Greek e Athenaze são os métodos preferidos. O relatório também indica os pontos fortes e fracos de cada um na opinião desses professores. Acom- 
Ferkelka, Anise A. G. D'O. A Lingüistica Aplicada em contexto digital e o ensino de grego, ..

panha o método uma fita cassete com a gravaçằo dos diálogos. Originalmente, o livro principal continha apenas os textos comentàdos e exercícios. A partir de 1995, passou a conter uma introdução gramatical para facilitar o estudo independente e se chama Independent Study Guide to Reading Greek (figura 4). Dentre os volumes suplementares, há ainda um compêndio gramatical e volumes de textos agrupados por temas (literatura sobre o mundo dos herôis, com textos comentados de Homero, Heródoto e Sófocles, e sobre o mundo intelectual, com textos de Tucídides, Euripides e Platão). Os textos do volume introdutório não são todos autênticos, mas são baseados em situaçōes encontradas na literatura. Tanto o Athenaze quanto Reading Greek possuem também um livro para o professor, com instruçōes de como conduzir as liçōes e respostas de exercícios. Apesar das críticas de leitores e especialistas (CUCD, 19951998), os métodos mencionados foram "pilotados" durante vários anos e continuam a ser adotados em universidades. Obviamentè, não considerando as diferenças e necessidades individuais de aprendizagem, seus aspectos de ordem afetiva e subjetiva, nenhum método, por mais fundamentado que seja, pode agradar a todos.

Em relação a uma visão de gramática, os espanhỏis pretendern inovar com a proposta de uma gramática funcional (Vázquez . Yamuza e Garrido, 1999. s.p.):

Desde el funcionalismo francés basado en los trabajos de Martinet $(1962 ;$ 1975) hasta la reciente Syntax que Van Valin y LaPolla han publicado en el marco de la Role and Reference Grammar (Van Valin, 1993; Van Valin; LaPolla, 1997) pueden citarse, entre otras, las siguientes: Functional Grammar (FG, Dik 1981; 1989; 1997), Systemic Functional Grammar (Halliday, 1985; 1994), Tagmemics (Pike, 1982), Lexical-Functional Grammar (Bresnan, 1982), Head Driven Phrase Structure Grammar (Pollard; Sag 1994), Construction Grammar (Fillmore, 1988), Autolexical Syntax (Sadock, 1991), Word Grammar (Hudson, 1984), Meaning-text Theory (Mel'chuk e Pertsov, 1986; Mel'chuck, 1987), Cognitive Grammar (Lakoff e Johnson, 
Rev. ANPOLL, n. 15, 11-4, jul./ dez. 2003.

1980; Lakoff, 1987; Langaker, 1987; 1991) y, además, los trabajos de autores aislados como Talmy Givón (1984; 1990; 1995), Susumu Kuno (1987), Paul Hopper y Sandra Thompson (1980; 1984; 1993), Anna Wierzbicka (1988; 1992).

La perspectiva funcional implica la asunción de que la función primera de toda lengua es la función comunicativa y que el estudio de la lengua debe llevarse a cabo con referencia a esta función (Dik, 1989: 2 ss.). Desde esta perspectiva la estructura formal de la lengua (categorias fonológicas, morfológicas y sintácticas) se ubica en un segundo plano y se consideră meramente instrumental (Siewierska, 1991: 3), en la idea de que, si se tomase como punto de partida de la descripción de una lengua dada cualquier aspecto de su estructura formal, omitiendo los aspectos relacionados con la función comunicativa, sólo podría obtenerse una descripción parcial y basada en aspectos secundarios. ${ }^{11}$ (Introducción)

No Brasil, o volume teórico de Murachco (2001) propōe uma reinterpretação da gramática grega tradicional, adaptando, justificando e fundamentando a nomenclatura de marcas morfológicas e sintáticas. Suas explicações visam a tornar a gramática mais acessivel e acompanham mais de mil exercícios corrigidos no segundo volume.

A experiência de aprendizagem da língua em nivel suficiente para uma leitura do grego, então, não parece ser fácil ou rápida. Ainda assim, parece haver uma cultura de estudo independente. $\mathrm{O}$ que faria o aluno persistir apesar de toda a dificuldade? Trzaskoma (2000-2002) diz ser uma loucura estudar grego sem um professor e adverte que a chance de êxito seria da ordem de $5 \%$, ou até de $10 \%$, para aqueles que procuram ler o Novo Testamento, em virtude de sua motivação: a crença de que esse è o livro mais importante que existe. Há quem diga que o estudo independente seja possível para pessoas inteligentes, como sugere, em tom de ironia, Harris (2002), professor de Middlebury College. Pessoalmente, acredito que

Ty Sem página; documento digital: http://clasicalo.us.es/andromaca/gfega/ introduccion.html 
FERrgira, Anise A. G. D'O. A Lingüistica Aplicada em contexto digital e o ensino de grego...

certos materiais didáticos podem acabar selecionando aprendizes que apreciam os exercicios do tipo "algébrico" como uma atividade intrinsecamente motivada, independentemente de levar a uma competência efetiva de leitura de um texto grego. Acredito também que o sucesso da aprendizagem seja muito mais dependente de dois fatores básicos do que do material de ensino: da motivação do aluno (que também tenha tempo disponivel) e do empenho do professor em dar suporte afetivo e cognitivo ao aluno, quando for o caso. Os materiais serviriam, assim, àquele aluno extremamente motivado (seja pela obtençāo de um diploma, seja pelo desafio da tarefa, seja pelo medo da reprovaçāo, ou por motivos religiosos). Esse resiste a qualquer método que o ajude a obter algum resultado positivo. Os demais aprendizes precisariam de um professor especial, cuja sensibilidade pudesse tornar o esforço algo muito maĩs atraente, compensando, com experiência, aquilo que os métodos não trazem. Como resultado, alguns alunos vão aprender de qualquer jeito; outros desistirão, nāo por incapacidade ou falta de habilidades cognitivas, mas por não se adaptarem a um tipo de abordagem de ensino, ou não terem a sorte de contar com um professor muito especial.

Uma contribuição importante da LA para o ensino de língua serià levantar, por meio de pesquisa, critérios para avaliação e seleção de métodos ou de estratégias de ensino, coerentes com uma visão social de linguagem e de aprendizagem de língua. A gramática não deveria ser um fim, mas um meio, um instrumento e uma estratégia. O fim será o uso que o aluno pretende fazer dessa língua. $\hat{E}$ importante que o uso da linguagem e os meios de letramento não fiquem distantes um do outro. O papel do professor é o daquele que avalia as necessidades dos alunos e cria, junto com o aprendiz, situações propicias e relevantes de uso da linguagem. Não se trata de nenhuma postura realmente inovadora. É coerente com Paulo Freire (1987) e seus seguidores no âmbito da educação de adultos. No âmbito da LA e do ensino de LE é uma postura corrente 
REv. ANPOLL, x. 15, p. 11-41, jui./dez. 2003.

(Widdowson, 1983; Cunningsworth, 1984). A novidade talvez seja pesquisar e adotar critérios no universo das Letras Clássicas para uma população adulta letrada diversa. De qualquer modo, mundialmente, percebe-se um esforço e uma tendência não só para renovar a visão gramatical da língua grega, como também para incorporar visões de língua, linguagem e de aprendizagem de língua discutidas no âmbito da Lingüística Aplicada e no ensino de linguas modernas.

Uma contribuição da LA relativamente recente ao ensino de LE é a abordagem empírica da Lingüística de Corpus. Ela, em si, como proposta de pesquisa, não é recente, mas sua disseminação tornou-se possivel, graças ao desenvolvimento dos recursos de têcnólogia de informação (McEnery e Wilson, 1996; Berber Sardinha, 2000; entre outros). Ela tem sido difundida como abordagem de descrição de linguagem, ensino de lingua e de Lingüistica, e técnica de processamento de corpora (Wichmann, Fligelstone, McEnery e Knowles, 1997). A aplicação de Lingüistica de Corpus no ensino de LE é defendida por Aston (1995; 1997) uma vez que o conhecimento esquemático visto como um fato social da linguagem fica evidenciado nos padrões de uso da lingua que as ferramentas de concordância podem extrair, ao serem aplicadas a um determinado corpus de estudo. Relacionados à Lingüistica de Corpus, podemos considerar os estudos que já fazem parte das grandes contribuições no âmbito da LA, que são aqueles ligados à compreensão de leitura. Um dos aspectos desse processamento se refere à capacidade do leitor produzir inferências (Tearney, Anders e Mitchel, 1987). Scott (1992) assumindo que inferir pelo contexto pode significar a inferência tanto pelo conhecimento esquemático de mundo e conhecimento prévio do leitor, quanto pelo conhecimento de diferentes niveis de co-texto, i.e., de texto adicional que acompanha o excerto a ser compreendido, verificou qual nivel de co-texto seria necessário à compreensão. Os lingüistas que trabalham com corpus diriam que ferramentas de concordância e de colocações (collocations) podem fornecer esse contexto aos estudantes da lingua (Berber Sardinha, 1999). 
Ferretra, Anise A. G, DO. A Lingüística Aplicada em contexto digital e o ensíno de grego...

No âmbito da lingua grega, os dicionários e métodos foram elaborados a partir de estudos do corpus, dentro de uma tradiçào, podemos dizer, centenária, baseados na pesquisa braçal demorada e minuciosa. Os bons dicionários e métodos exemplificam variações de sentido e uso com textos autênticos da literatura de diferentés periodos. Há muitas publicaçôes de Concordances das obras clássicas, tais como das de Homero, Platão, Hesíodo etc. (Minton, 1976). Na esfera específica da LA se faz notar o interesse do processamento de corpus de grego monotônico para o grego moderno (King, 1997), mas desde o final dos anos setenta, existe o projeto Thesaurus Linguae Graecae (TLG) visando à construção de corpora eletrônícos, realizando a digitalização dos textos gregos de diferentes épocas e gêneros (Berkowitz e Squitier, 1990). Com os recursos dos corpora eletrônicos, com textos digitalizados, tais projetos, como o próprio TLG e Perseus ${ }^{12}$ (Crane, 1996-2002), aliados às ferramentas de análise lexical, análise morfológica, dicionários eletrônicos, a pesquisa dos usos da língua grega e seu reconhecimento ficam mais accessiveis. O Perseus Project possui ferramentas on-line para efetuar concôrdâncias e busca de palavras em proximidade. Em publicação anterior desta revista, indiquei pesquisas com corpus eletrônico de línguas antigas e relatei uma pesquisa de corpus de língua grega (Ferreira, 2001). O desenvolvimento de tecnologia para a Lingüística de Corpus favorece também o ensino e aprendizagem no contexto digital. A interface da Lingüistica de Corpus e das línguas antigas começa a se destacar com eventos específicos em que aparecem trabalhos relativos à língua grega, como o que se refere à possibilidade de se trabalhar com o grego helenístico como um problema para a Lingüística de Corpus (Porter e O'Donnell, 2001), apesar dos problemas levantados com o uso de corpora diacrônicos (Rissanen, 1989). O fato é que não há ainda estudos sobre defini-

\footnotetext{
12. O Perseus Project existiu em video-disco e putras formas eletrônicas, antes da exis tência da Internet e da Web.
} 
Rev. ANPOLL, n. 15, p. 11-41, jul./dez. 2003.

ções ou descrições de corpora representativos de gềneros na língua grega antiga.

\section{O ensino-aprendizagem em contexto digital da Welo e programa de curso}

Como o uso de computadores entre os classicistas não é algo novo (Latousek, 2001) sua transferência para o universo da Internet foi uma decorrência natural. Hoje, além dos tutoriais de Mastronarde (1999-2002), disponiveis na Internet, os métodos de ensino e cursos de grego clássico em ambiente digital começam a crescer em programas de educação continuada de universidades prestigiosas, como Harvard e Universidade da Califórnia. Open University, conhecida instituição de ensino a distância também oferece cursos de grego. Tais cursos são restritos a alunos matriculados e pagantes, mas muitas vezes o conteúdo ou syllabus, com alguns materiais, ficam disponiveis para acesso irrestrito. O portal belga, Greek grammar on the Web, ${ }^{13}$ de Marc Huys, professor do departamento de Clássicas da Universidade Católica de Leuven, apresenta uma lista de cursos on-line e recursos de língua grega de diferentes niveis e temas disponiveîs na Web, com um pequeno resumo e avaliação do serviço. É curioso que esse portal seja justamente denominado Greek grammar. O que se percebe nas resenhas dos diferentes cursos é a preocupação em informar, deixar textos disponiveis, bem como oferecer tutoriais para a prática gramatical. A quantidade de recursos (e não cursos) eletrônicos disponiveis na Internet para Letras Clássicas é considerável, levando-se em conta que se imagina um público interessado muito reduzido. O Perseus Project e o TLG também marcam sua presença na rede. O primeiro, além, de ter textos em língua original vinculados a tradução e ter todo o léxico vinculado a dịcionário, possui ferramentas especiais para

13 http://perswww.kuleuveri.ac.be/ p3481.184/greekg.htm 
Ferrerra, Anise A. G. D'O A Lingüistica Aplicada em contexto digital e o ensino de grego....

consulta on-line, tais como busca de palavras em contexto de obras, dicionário grego-inglês e análise morfológica de todas as palavras gregas da base de dados presentes nos textos. Fora do escopo da língua, possui acervo iconográfico de vasos e moedas. Seu acesso ể gratuito. O segundo, TLG - Thesaurus Linguae Graecae, Projeto da Universidade da Califórnia em Irvine, embora ofereça um número maior e considerável de textos do que o Perseus, tem acesso restrito aos assinantes. Esses projetos foram apontados acima principalmente como ferramentas de pesquisa, mas podem servir como instrumentos para fins educacionais (Mahoney, 2001). Com algumas horas na Internet, portanto, o estudante de grego, orientado por alguém mais experiente, é capaz de encontrar inúmeros recursos gratuitos, entre software, tutoriais e bases de dados bibliográficos (Pantelia, 2002) que podem compor um trabalho didático-pedagógico.

No Brasil, os métodos e cursos de grego na Internet ainda sãó raros. Há alguns serviços de informação sobre literatura e algumas tentativas de portais relativos a temas populares, tais como mitologia grega e teatro. Quanto a curso a distântica, há a iniciativa proposta pelo professor da Universidade Federal do Paraná, Jorque Piqué, que fundou o Centro Virtual de Estudos Clássicos. Piqué e eu fomos colegas do curso de grego (parte da graduação e mestrado) da USP e começamos a explorar os potenciais da Internet praticamente na mesma época, em 1994, quando Piqué assumiu sua posição de professor na universidade a que está filiado e eu integrava o projeto federal do Ministério da Ciência e Tecnologia que implantou a Internet acadêmica no Brasil, a Rede Nacional de Pesquisa. Naquela época, tive a oportunidade de divulgar os recursos acadêmicos da Internet e ajudar colegas da área de Clássicas a adotarem o uso dessas novas tecnologias, oferecendo seminários e minicursos em congressos (Ferreira, 1994; 1995; 1997a; 1997b). Mas foi Piqué, em 1997, quem ofereceu o primeiro curso de grego na Web. O curso se apóia no método de C. Ruck, ${ }^{14}$ Ancient Greek, a

td. Cf. tồpicos nos quais ò método đe Ruck se organiza, figura 5. 
Rev. ANPOLL, n. 15, p. 11-41, jul./dez. 2003.

new approach, traduzido e adaptado pelo próprio Piqué. Ele, assim como muitos acadêmicos, se tornaram usuários experientes da tecnologia, mas encontraram muitas dificuldades em explorar adequadamente o meio digital como espaço de ensino-aprendizagem. É uma tarefa quase impossivel de se empreender, sem o auxílio de outros professores "letrados" nas chamadas NTIC, novas tecnologias de informação e comunicação. É preciso uma equipe integrada, não só de conhecedores da matéria, mas de usuários experientes da tecnologia e de bases didático-pedagógicas orientadas ao contexto digital. Um perigo enfrentado por todos que passam a exercer a docência on-line é tratar o ambiente digital da mesma forma que a sala de aula ou de tentar transformar o curso em um "livro digital" desprovido do aspecto interativo das relações entre professor e alunos existentes na sala de aula. Se nossa hipótese de que, face-aface, o aluno permanece no curso pelo seu alto nivel motivacional e pela presença marcante do professor, a mediação tecnológica pode ser uma barreira para o estabelecimento da interação entre professor e alunos, e causar transtornos de ordem operacional que diminuam os niveis motivacionais.

Há inúmeras variáveis que podem afetar a aprendizagem on-line. Elas podem referir-se ao nivel de letramento tecnológico ou mesmo à habilidade de administrar o próprio tempo, que passa a ser controlado pelo aluno e não pelo horário institucional. A necessidade de letramento digital é bastante documentada como um requisito essencial para o sucesso de qualquer iniciativa educativa na Web (McCormack e Jones, 1997; Horton, 2000). Mas o aluno, principalmente o adulto, para se manter motivado precisa, no minimo, obter ou perceber êxitos e perceber um sentido, valor ou relevância na sua empreitada (Wlodkowski, 1993). O papel da tecnologia, se for empregada adequadamente, é de ajudar a dar significado à aprendizagem. Jonassen (1999a, 1999b) dentro de uma perspectiva construtivista pressupōe que o conhecimento é construído e não transmitido, resulta da atividade, está ancorado no contexto em que a atividade ocorre; requer expressão ou re- 
presentação do que é aprendido; o significado desse conhecimento está na mente daquele que conhece e pode ter múltiplas perspectivas, é resultante de um problema, questão ou confusão apossado pelo que deseja conhecer, é compartilhado com outros e pode resultar da interação. Pressupõe, ainda, que o significado é distríbuído pelas ferramentas humanas e, conseqüentemente, pela cultura e comunidade, e que os significados não são criadós todos da mesma forma. Assim, aponta cinco atributos críticos da aprendizagem ou da criação de significado. Ela é ativa, reflexiva ou articulatória, intencional, i.e., pressupõe um objetivo, é autêntica, i.e., ocorre em um contexto complexo e autêntico e é cooperativa (ou colaborativa e conversacional), uma vez que, no mundo real, problemás são resolvidos em interação e colaboração com outros membros da comunidade.

Se não parece uma empreitada nada simples, por que oferecer cursos de grego na Internet? O motivo principal de alguém propor uma experiência de aprendizagem através da Internet é ampliar e difundir essa experiência. Há outros, naturalmente, maș não serão discutidos aqui. Com a Internet, é possivel expandir o alcance do ensino da língua para fora dos grandes centros, sem o ônus do deslocamento, seja para o professor, seja para o aluno, quando esse deslocamento é difícil e às vezes até impossível. Ê bem verdade que há um ônus de outro tipo, como a necessidade de desenvolvimento tecnológico apropriado, que envolve a participação de um corpo técnico e de equipamentos sempre atualizados. Contudo, a ampliação de um corpo discente é bem-vinda, pois cria demanda para a ampliação de um corpo docente apto a desempenhar seu papel no contexto digital, evitando a necessidade de criação de mais salas de aula. Ao mesmo tempo, o aumento do corpo docente pode promover o surgimento de novos pesquisadores, mais tradutores e críticos para difundir, em escalas maiores e mais profundas, o conhecimento da lingua e da cultura grega também para outras esferas profissionais. 
Rev: ANPOLL, 1., 15, p. 11-41, jul./dez. 2003.

A LA em contexto digital tem, então, aî, sua participação especial, por meio de suas várias interfaces: a informática na Educação (Almeida, 2001): a tecnologia educacional ou educação com tecnologia de informação e comunicação (Jonassen, 1996; Horton, 2000); Educação a Distância (Cyrs, 1997; Belloni, 1999); estudos de interação homem-computador e facilidade de uso de interfaces (Nielsen, 2001), bem como os estudos sobre as implicações pedagógicas dessa interação (Silva, 2000). É preciso lembrar aqui que a contribuição da Lingüística no âmbito da análise textual, análise da interação, do discurso e descrição de gêneros em uso em diferentes contextos, como sala de aula (Costa, 1992; Dionisio et al., 2002), trabalho ou negócios (Collins et al., 1997) está expandindo seus domínios e tem afetado diretamente a compreensão do uso da linguagem no próprio contexto digital (Davis e Brewer, 1997; Herring, 1999; 2001; Lemke, 1998; Chanier e Pothier, 1998; Collison, Elbaum, Haavind e Tinker, 2000; Sabbag, 2002; Abreu, 2002).

Pensando nessas interfaces, foi criado o grupo de pesquisa Edulang, do Programa de Estudos Pós-graduados de Lingüistica Aplicada e Estudos da Linguagem da PUC de São Paulo, especialmente dedicado à investigação do ensino e da aprendizagem de língua on-line ${ }^{15}$ Desde 1997, temos oferecido, na Internet, no nìvel de extensão, cursos de língua estrangeira e materna. Esses cursos não são apenas serviços prestados à comunidade, mas são, também, contextos de coleta de dados de pesquisa sobre o ensino e aprendizagem no contexto digital da Web. Criamos ${ }^{16}$ um projeto amplo, intitulado LA em Contexto digital. ${ }^{17} \mathrm{O}$ grande desafio é planejar e criar cursos que atendam a populações especificas, se afinem com uma visão social de linguagem e uma visão de ensino e aprendizagem de língua, sejam adequados ao ambiente digital do.

15 Cf. Descrição do grupo: http://lael.pucsp.br/edulang/contents.html, cadastrado no Diretório de Grupos de Pesquisa do CNPq.

16 Lider do grupo no Diretório de Grupos de Pesquisa do CNPq, Heloisa Collins.

17. Projeto interinstitucional temático. 
Ferreira, Anise A. G. D'O. A Linguística Aplicada em contexto digital e o ensinö de grego...

porto de vista do uso da linguagem, adotem também uma visão e procedimentos adequados para a aprendizagem a distância mediada por computador e proponha práticas didático-pedagógicas apropriadas e efetivas. O ambiente virtual é propicio à evasão, que costuma ser grande quando o curso não se destina à obtenção de graú em qualquer nivel, mesmo que ofereça um certificado e haja exigência de freqüência, ${ }^{18}$ ou que seja totalmente gratuito. Já sabemos que o aluno motivado pode pérmanecer em um curso presencial, independentemente da qualidade do método, mas ele não vai permanecer em um curso on-line independentemente da qualidade do acesso, da interface, dos materiais e da qualidade da interação com o professor. É preciso que ele perceba que vai obter algum grau de sucesso nas atividades propostas. No ambiente on-line, há barreiras de ordem tecnológica, como funcionamento adequado da conexão e do computador, que podem comprometer a obtenção desse nível mínimo de sucesso. É preciso que o curso seja desenhado de tal forma que o aluno fique disposto a vencer até mesmo esse tipo de barreira. Os resultados das primeiras experiências do grupo Edulang foram encaminhados para publicação (Collins e Ferreira, 2002), bem como já despontam algumas dissertaçōes e teses (Lacombe, 2000; Weyersbach, 2002; Sabbag, 2002; Fontes, 2002). Especial preocupação tem sido dispensada à formação do professor em que pesam bastante as questōes do letramento tecnológico no processo de aprendizagem (Ramos e Freire, 1999; Ferreira, 1999). Embora se refiram ao ensino e aprendizagem de linguas modernas, tal preocupação tem gerado algumas pistas e procedimentos que se aplicam, em hipótese, ao planejamento do curso para a aprendizagem também da língua grega no contexto digital.

1.8 A presença, freqüência ou permanência em curso on-line ê verificada pelos registros automáticos de acesso ao curso, registro de mensagens lidas e enviadas, e de tarefas executadas. 
Rev. ANPOLL , n. 15, p. I 1-41, jul./dez. 2003.

\section{Algunas considerações para uma proposta de curso on-line de grego}

- Conhecimento é definição do público-alvo: ampliação da demanda O designer do curso on-line precisa conhecer e definir seu público-alvo se adotar uma visão social e funcional da linguagem e pressupor que a aprendizagem significativa depende de uma autenticidade e uma intencionalidade do fazer. Um modo de definir esse público é saber o que os alunos do curso pretendem ou querem com a língua grega. A resposta é fundamental para a elaboração de tárefas com metas autênticas de uso da língua e de estratêgias adequadas. Assim, podem ser criados e discutidos no curso problemas ou situações reais do uso da língua. Os métodos de grego em língua portuguesa foram criados visando a uma população de futuros professores de Letras. De fato, poucos serão professores de grego, pois não há muitas vagas em instituições de ensino para desempenhar tal função. Há de se considerar uma utilização especial desse material já existente ou a criação de outros voltados para outros públicos ou públicos mais especificos, considerando-se, inclusive, a possibilidade de negociação do currículo durante o curso.

- Atividades que teriham natureza colaborativa visando a metas auttênticas

Um curso on-line que utilize recursos de comunicação pode aumentar substancialmente o nível de interação entre alunos e professor e a produção conjunta de ações por parte de alunos. Se o professor on-line considera importante a interação e colaboração no processo de aprendizagem, não basta assumir que elas ocorrerão naturalmente. A mediação do professor e a natureza das atividades são fundamentais para que elas ocorram. Ao mesmo tempo, as atividades que reforçam o uso da linguagem em contextos autênticos favorecem a percepção da relevância da aprendizagem e do desenvolvimento dos processos, As tarefas colaborativas e o alto nivel de 
Ferreira, Anise A, G. D:O. A Lingüistica Aplicada em contexto digital e o ensino de grego...

interação entre aprendizes năo costumam acontecer em ambientes presenciais e não são prevístos nos métodos, uma vez que a aprendizagem da gramática se apóia em um esforço cognitivo inđividual. É um desafio imaginar tarefas colaborativas que mantenham o nível motivacional dos alunos, visando ao uso de estratégias cognitivas para leitura da língua grega.

- Uso adequado de estratégias para proposição "dinâmicas de in" teração"

Sabendo-se que a interação é tão importante para manter a motivação do aluno no curso de grego presencial, é de se supor que no contexto digital ela seja ainda mais importante. Contudo, no ambiente digital, o programa, materiais e atividades precisam seguir princípios para uma aprendizagem significativạ; è preciso levar em conta os desejos e as necessidades dos alunos, a relevância e a finalidade de cada atividade prática. A qualidade da interação parece vital para que o aluno se mantenha no curso. Hả muitas ferramentas disponiveis on-line e estratégias de interação têm sido investigadas, Além disso, o ambiente digital é propício ã formação de uma comunidade de aprendizagem que pode dar suporte tanto cognitivo quanto afetivo, mas não sabemos o que de fato pode ser efetivo e como desenvolver uma interação e trabalho colaborativos adequados no âmbito do ensino-aprendizagem da língua grega.

\section{- Planejamento e uso de ferramentas adequadas}

Para um bom aproveitamento dos recursos, há a necessidade de os instrutores ou designers conhecerem ferramentas próprias para administração de curso. É preciso decidir a adoção de courseware ou ferramentas de autoria de curso para Web. Posteriormente, é preciso decidir as ferramentas, dentro do courseware a serem adotadas: fer ramentas de comunicação síncrona, assíncrona? testes automáticos? ferramentas para organização do estudo? e assim por diante. 
Rev, ANPOLL, in. 15, p. 11-41, jul./dez. 2003 .

- Seqüencias de aprendizagem, nas formas e dosagem apropriadas para o público-alvo

Depois de decididas as ferramentas, é preciso pensar nas seqüências de atividades. A Web possibilita formas diferentes de dispor essas seqüências. Até que ponto métodos já existentes poderão ser aproveitados como tutoriais? Considerando-se a complexidade do processo de aprendizagem da lingua grega, há de se pesquisar, no contexto on-line, as seqüências mais apropriadas para cada público. A abordagem de Lingüistica de Corpus pode ser bastante útil na separação e descrição dos gêneros para que se proponham seqüências adequadas ao ensino de determinados padrões estabelecidos como metas lingüísticas do público-alvo. É importante ressaltar também a grande quantidade de materiais eletrônicos e recursos disponiveis na rede para o estudo de grego. Esses recursos podem ser utilizados na proposição de seqüências e de estratégias.

- Leitura e escrita em materiais hipertextuais ou hipermidiáticos: interface de usuário amigável e de navegação fácil

É de conhecimento corrente que a escrita e a leìtura na Web são diferentes da escrita e da leitura no papel, exigindo do leitor e do escritor habilidades ou estratégias diferenciadas para o meio. Da mesma forma, a interação on-line tem suas características. Um desafio é investigar a escrita de instrução mais adequada para as finalidades propostas em um curso de grego. Cabe investigar, portanto, os modos de leitura para compor uma escrita que favoreça a compreensão de instruções e uma interface amigấvel e de navegação fácil.

- Letramento digital e uso dos recursos eletrônicos para o estudo da lingua grega

O desapontamento causado pela falha ou desconhecimento de recursos de informática e da Internet é grande mesmo para os usuários experientes; está para nascer aquele que nunca amaldiçoou 
FERRETRA, Anise A. G. D'O. A Linguística Aplicada em contexto digital e o ensirta de grego. .

seu computador. As conseqüências dessa frustração sobre uma proposta de ensino on-line podem ser fatais em relação ao aluno e difíceis em relação à formação do professor que tem problemas ele próprio com a tecnologia. A lingua grega, empregando outro alfabeto, requer o conhecimento de ferramentas específicas para visualização dos caracteres gregos. É um fator complicador na preparação de material, mas também é superável. Hoje, os browsers permitem a visualização de praticamente quaisquer idiomas com quaisquer caracteres, embora os editores de páginas para difusão em Web ain * da possuam algumas limitações.

\section{Conclusão}

Procurel indicar neste artigo como alguns focos de pesquisa na LA podem contribuir para uma proposta de desenvolvimento de aplicações educacionais, no contexto digital da Web, voltadas ao ensino/aprendizagem da lingua grega antiga em diferentes niveis e para diferentes fins. Foram apresentados os tópicos comumente estudados pela LA, tais como a abordagem instrumental, visão social da linguagem e de aprendizagem, processos e estratégias de leitura, Lingüística de Corpus, análises de textos, de discurso e de interação etc, como possiveis contribuições ao âmbito do ensino-aprendizagem de grego antigo. No âmbito da interface da LA em contexto digital, algumas considerações preliminares foram feitas para o planejamento de experiências de ensino/aprendizagem da língua grega. Elas dizem respeito às necessidades de diferentes comunidades de aprendizagem, à elaboração de materiais que resultem em aprendizagem significativa, às estratégias de comunicação e modos interação on-line, à manutenção da motivação e ao letramento tecnológico de professores e alunos. Considero tal empreendimento um grande desafio, tendo em vista que se trata de uma lingua que não é usada como instrumento de comunicação atual, mas como instrumento e objeto de leitura, reflexão, estudo e compreensão de 
outros textos, dentro de diferentes comunidades discursivas, ou de subgrupos acadêmicos e profissionais, e que tal perspectiva não é comum na esfera das Letras Clássicas como foco de pesquisa.

A lingua e cultura gregas possuem reflexos marcantes na cultura ocidental em geral e nas culturas de lingua portuguesa, afetando diversos segmentos acadêmicos e profissionais. Reconhecendo sua importância para compreensão de nossa própria cultura, considero que seja um desafio necessário; uma oportunidade para ampliar os horizontes da educação clássica. Ao mesmo tempo, não vejo como um desafio impossivel de ser realizado, a julgar pelos resultados, ainda que preliminares, obtidos através de pesquissas da multifacetada Lingüística Aplicada em contexto digital. Há muitas questões que só poderão ser respondidas com a realização efetiva de tal proposta. Espero, com esta reflexão, despertar o interesse de colegas classicistas e lingüistas, entre outros especialistas, e incentivá-los a formar equipes interinstitucionais com o objetivo de discutir, pesquisar e desenvolver propostas de ensino/ aprendizagem de grego na Web.

ABSTRACT: This article defends the position that Applied Linguistics can contribute to the development and implementation of Web-based courses in Ancient Greek, although it is an uncommon subject in the field of Applied Linguistics. Possible contributions to classical Greek teaching/learning come from research in: the teaching methodology of language for specific purposes, language use in social contexts and its learning, reading comprehension, corpus linguistics, and interaction analysis. Some preliminary guidelines for designing an online course for learning Greek are proposed, based on multifaceted Applied Linguistics research in digital teaching/learning contexts.

KEYWORDS: Applied Linguistics and Classics: online Greek course; Applied Linguistics to Greek teaching design; teaching and learning Greek on the Web. 
Ferpere, Antse A. G. D'O. A Lingüistica Aplicada em contexto digital e o ensino de grego...

\section{BIBLIOGRAFIA}

ABREU, L. (2002) O chat educacional: o professor diante desse gênero emergente. In: MACHADO; Dionisio; BezErra (Eds.). Gêneros textuais e ensino. Rio de Janeiro: Lucerna.

Almeida, F. J. (Coord.). (2001) Educação a distância. Formação de professores em ambientes virtuais e colaborativos de aprendizagem. São Paulo: Projeto Nave, PUC-SP.

Aston, G. (1995) Corpora in language pedagogy: matching theory and practice. In: Cook; SeIdlhofer (Eds.), Principle \& practice in applied linguistics. Oxford: OUP.

- (1997) Enriching the learning environment: corpora in ELT. In: Wichmann et al. (Eds.). Language teaching and corpora. New York: Longman.

BaILly, A. (1963) Dictionnaire grec-français. Paris: Hachette.

BAKer, Alison (2001) Ancient Greek with thrasymachus: a Web site for learning Ancient Greek. Calico Journal, 18(2), p. 393-400,

Balme, M.; Lawall, G. (1990) Athenaze: an introduction to ancient Greek. Oxford: OUP.

Barbot, M.-J. (1998) Présentation. Ressources d'apprentissages: excès et accès. Études de linguistique appliquée, 112, oct-déc. [On-line]: http:// www.chass, utoronto.ca/french/frenetica/ela.htm

Barros, H. P. (1962) Propedêutica ao grego. São Paulo: Herder.

Barros, D. L. P. (1999) Text and discourse studies in Brazil. DELTA, n. 15 (spe), p. 183-99.

Belloni, M. L. (1999) Educação a distância. Campinas: Editora Autores Associados.

Berber Sardinha, À. P. (1999) Usando WordSmith Tools na pesquisa lingüística. DIRECT Paper 40. LAEL, Catholic University of São Paulo/ AELSU, University of Liverpool: Brazil/United Kingdom. [On-line]: http:/ /lael.pucsp. br/direct/DirectPapers40.pdf

. (2000) Lingüistica de Corpus: histórico e problemática. DELTA, n. 16 (2), p. 323-67. [On-line]: http://www.scielo.br/

Berkowitz, L.; Sguritier, K. A. (1990) Thesaurus linguage graecae, Canon of greek authors and works. New York/Oxford: OUP.

A bibliografia completa encontra-se em http://lael.pucsp.br/ anise/artigo_anpoll.html 
Rev. ANPOLL, n. 15, p. I 1-41, jul./dez. 2003.

CArdoso, Z. A. (1994) Letras clássicas hoje. Revista do Instituto de Estudos Avançados, 22. [On-line]: http://www.usp.br/iea/revista/revista22/ letrasclassicas.html

Chanięr, T.; Pothier, M. (1998) Présentation, hipérmedia et apprentissage des langues. Études des linguistique appliquée, 110, avril-juin. IOnline]: http:// lifc,univ-fcomte.fr/RECHERCHE/P7/pub/elaintro,htm 